\title{
AVALIAÇÃO TÉCNICO-ECONÔMICA DO PROCESSO DE OBTENÇÃO DE OLIGOPEPTÍDEOS E ETANOL A PARTIR DA CASCA DA SOJA
}

\author{
C. PRETTO ${ }^{1}$, L. C. MIRANDA ${ }^{2}$, P. F. SIQUEIRA ${ }^{2}$, P. W. TARDIOLI ${ }^{1}$, R. C. GIORDANO ${ }^{1}$, R. L. \\ C. GIORDANO ${ }^{1}$ e C. B. B. COSTA ${ }^{1}$ \\ ${ }^{1}$ Universidade Federal de São Carlos, Departamento de Engenharia Química \\ ${ }^{2}$ IMCOPA - Importação, Exportação e Indústria de Óleos S.A \\ E-mail para contato: caliane@ufscar.br
}

\begin{abstract}
RESUMO - O processo de obtenção do óleo e do farelo de soja gera como subproduto a casca da soja. Atualmente, esta é, majoritariamente, utilizada para alimentação animal ou queimada na caldeira para gerar energia para a própria fábrica. Outras finalidades para este subproduto que aumente a rentabilidade da empresa têm sido objeto de estudo nos últimos anos. O uso da casca para a produção de oligopeptídeos e etanol já foi estudada em escala de bancada. O presente trabalho teve como objetivo fazer uma avaliação técnico-econômica de uma possível planta de produção de oligopeptídeos e etanol a partir da casca da soja, analisando quais parâmetros são fundamentais para a viabilidade econômica desse processo. Resultados indicam que os preços das enzimas, tanto a protease quanto a celulase, utilizadas e o preço do etanol e dos oligopeptídeos influenciam na viabilidade deste processo.
\end{abstract}

\section{INTRODUÇÃO}

A casca da soja é um subproduto do processo de obtenção do óleo e farelo de soja. Atualmente, seus principais usos são como ração para ruminantes, suínos e aves e para geração de vapor e energia em caldeiras das próprias fábricas de processamento do grão (SILVA, 2004; IMCOPA, 2014). Porém, pesquisas têm sido realizadas com o objetivo de agregar valor a este subproduto, aumentando, assim, o rendimento das empresas. Por ser um material rico em celulose, aproximadamente $36 \%(\mathrm{~m} / \mathrm{m})$ de sua composição (ver Tabela 1), a maioria dos trabalhos publicados visa a produção de etanol (SCHIRMER-MICHEL et al., 2008; MIELENZ et al., 2009; ROJAS, 2012).

De fato, a produção de etanol a partir da casca da soja parece ser uma boa alternativa devido a esta grande quantidade de celulose e ao aumento da procura por biocombustíveis. Além disso, a proteína presente na casca de soja (aproximadamente $15 \%, \mathrm{~m} / \mathrm{m}$, Tabela 1) também pode ser hidrolisada para a obtenção de oligopeptídeos. Existem estudos que sugerem que oligopeptídeos, principalmente di e tri-peptídeos, são melhores absorvidos pelo organismo do que a proteína intacta ou mesmo a quantidade equivalente em aminoácidos livres (CLEMENTE, 2000). 
Tabela 1 - Composição da casca da soja

\begin{tabular}{|c|c|}
\hline Componente & $\%(\mathrm{~m} / \mathrm{m})$ \\
\hline Celulose & 35,80 \\
\hline Hemicelulose & 23,10 \\
\hline Lignina & 9,10 \\
\hline Extrativos & 5,00 \\
\hline Cinzas & 4,00 \\
\hline Proteínas & 15,40 \\
\hline Pectinas & 4,20 \\
\hline
\end{tabular}

Fonte: Rojas (2012).

Os trabalhos publicados sobre a utilização da casca da soja como biomassa para a produção de etanol ainda são escassos e apenas em nível de laboratório, sendo que não foi encontrado nenhum que analise a viabilidade econômica do processo. Assim, este trabalho teve como objetivo realizar uma análise técnico-econômica preliminar da produção de etanol e oligopeptídeos a partir da casca da soja em escala industrial a partir de dados obtidos na literatura. Até o momento foram feitas análises considerando a obtenção destes produtos em um processo isolado, mas o que se pretende, em um trabalho futuro, é integrar este processo a uma planta de extração de óleo e farelo de soja.

Vários fatores influenciam na viabilidade de uma planta, como a capacidade instalada, o custo dos insumos e preço de venda dos produtos, a tecnologia disponível, os equipamentos utilizados, etc. Para este trabalho, optou-se por, definida uma capacidade de produção e um determinado arranjo produtivo, determinar a influência dos preços dos principais insumos e produtos na viabilidade desta planta.

\section{MATERIAIS E MÉTODOS}

Para a avaliação técnico-econômica do processo de extração de oligopeptídeos e produção de etanol a partir da casca da soja, utilizou-se o software SuperPro Designer 7.0. Para os dados de rendimento e sequência de operações foram utilizados os dados obtidos por Rojas (2012). Os equipamentos utilizados para a produção em escala industrial tiveram como base os trabalhos de Dias (2008 e 2011).

\subsection{Dados Obtidos em Escala de Laboratório}

Os resultados obtidos por Rojas (2012) para a extração de oligopeptídeos e a produção de etanol da casca da soja em escala de laboratório foram utilizados como dados de partida para o presente trabalho. Vale ressaltar que não era foco daquele trabalho a otimização do processo, e, por alguns experimentos preliminares feitos pela autora, foram comprovados condições que melhoram o rendimento do processo, porém estas condições melhores não apresentam dados suficientes para modelagem. Como conseqüência, rendimentos melhores ainda podem ser obtidos.

A Figura 1 apresenta a sequência de etapas utilizadas. Primeiramente, a casca é misturada com 
água na proporção de 1:9 para a realização da hidrólise protéica. A hidrólise foi realizada em um reator batelada com agitação mecânica durante $5 \mathrm{~h}$ a $60^{\circ} \mathrm{C}$ e pH 9. A enzima utilizada foi a Novo-Pro $\mathrm{D}$ fornecida pela Novozymes com concentração de $1 \%$ enzima $\left(\mathrm{m}_{\text {enzima }} / \mathrm{m}_{\text {proteína }}\right)$. Após a hidrólise, a mistura foi filtrada e seca em estufa a $60^{\circ} \mathrm{C}$. Como resultado, $56,9 \%$ das proteínas foram solubilizadas, a maioria com tamanho inferior a $6500 \mathrm{Da}$. $\mathrm{Na}$ fração líquida são obtidos os oligopeptídeos e na sólida, grande parte da celulose (75\%), hemicelulose, lignina e outros sólidos não solubilizados.

O pré-tratamento do material lignocelulósico foi feito com ácido diluído. A fração sólida obtida na etapa anterior foi colocada em autoclave por $40 \mathrm{~min}$ a $120{ }^{\circ} \mathrm{C} \mathrm{com}$ ácido sulfúrico $3 \%$ (v/v). Ao fim, a mistura foi filtrada e seca em estufa novamente. Ao final, foram removidos $65,6 \%$ da hemicelulose, na forma, principalmente, de pentoses.

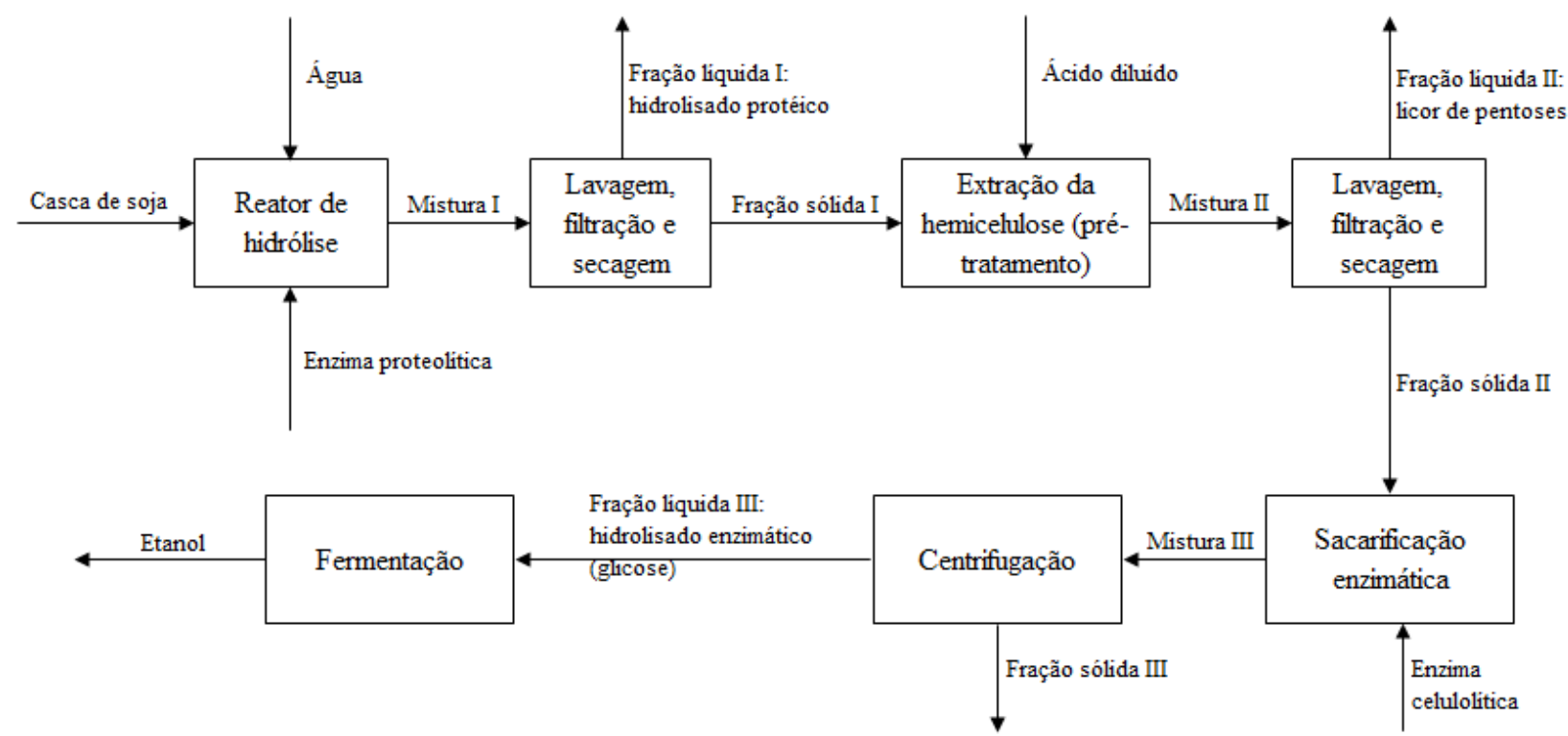

Figura 1 - Etapas utilizadas na produção de oligopeptídeos e etanol da casca da soja.

A hidrólise da celulose foi feita com a enzima Acellerase da Genencor, fornecendo uma carga de 7 e $20 \mathrm{FPU} / \mathrm{g}$ de celulose. Os dados utilizados neste trabalho são com base na carga de $20 \mathrm{FPU} / \mathrm{g}$ de celulose. A reação foi realizada a $50{ }^{\circ} \mathrm{C}$ por $72 \mathrm{~h}$ em $\mathrm{pH} 4,8$. Após a reação, o material foi centrifugado por $10 \mathrm{~min}$ a $2500 \mathrm{rpm}$ e $4{ }^{\circ} \mathrm{C}$. A conversão de celulose em glicose foi de $55 \%$. $\mathrm{Na}$ fração sólida, foi retirada, principalmente, a lignina. A separação sólido-líquido após a sacarificação enzimática permite que se obtenha uma fração sólida contendo lignina e celulose não hidrolisada. A fração líquida, rica em glicose, foi utilizada na fermentação com a levedura Sacharomyces cerevisiae da marca Fleischmann durante 135 min a $30^{\circ} \mathrm{C}$. O rendimento em etanol foi de 45,6\% e em relação ao teórico de $89,3 \%$. Para a modelagem, o tempo de fermentação utilizado foi de $8 \mathrm{~h}$ (com base em Dias, 2011). 


\subsection{Descrição do Processo Proposto em Escala Industrial}

Para a simulação, fixou-se em 7920 h o tempo de operação anual, com o processamento de aproximadamente 36,2 mil toneladas de casca por ano. A IMCOPA - Importação, Exportação e Indústria de Óleos S.A. é uma empresa esmagadora de soja localizada em Araucária-PR. Utilizando esta empresa como exemplo, processar esta quantidade de casca seria o equivalente a utilizar aproximadamente $84 \%$ do total de casca gerada anualmente como subproduto da obtenção do óleo e farelo de soja.

Para a escolha dos equipamentos utilizados no processo, tomou-se como hipótese que o tratamento para a fermentação da glicose proveniente da hidrólise da celulose da casca é muito parecido ao que se dá com o bagaço da cana-de-açúcar. Desta forma, os equipamentos escolhidos foram os mesmos utilizados por Dias (2011) para a fermentação da glicose proveniente da hidrólise da celulose do bagaço de cana para a produção de etanol de segunda geração. A Figura 2 apresenta a proposta da planta do processo.

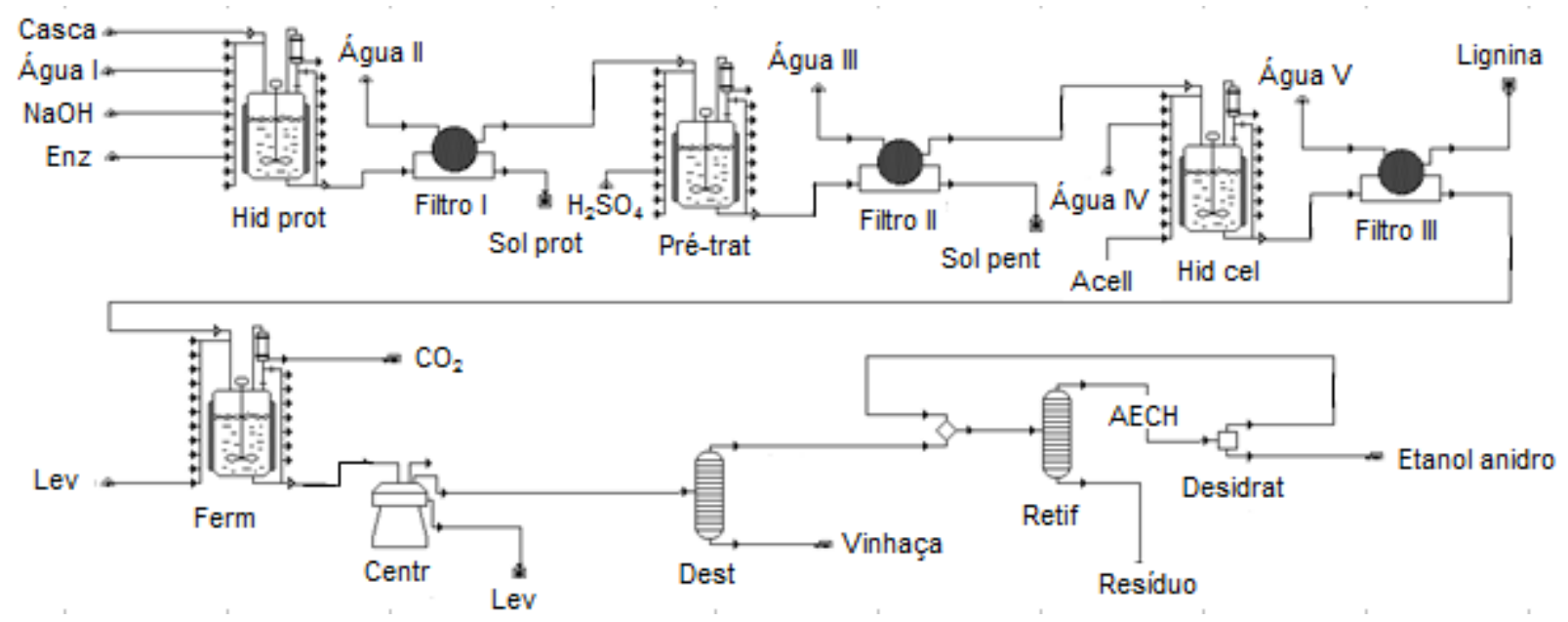

Figura 2 - Proposta para a planta de processamento da casca de soja pra obtenção de oligopeptídeos e etanol.

Após as reações de hidrólise das proteínas (Hid prot), extração da hemicelulose (Pré-trat) e hidrólise da celulose (Hid cel), em cada etapa, a mistura obtida foi filtrada. Depois da fermentação (Ferm), o vinho foi centrifugado para a separação das leveduras. Finalmente o vinho delevedurado que sai da centrífuga segue para a destilação (Dest e Retif) onde considerou-se a obtenção de álcool hidratado com aproximadamente $93 \%$ em massa de etanol e depois da desidratação (Desidrat) considerou-se $99,6 \%$ em massa de etanol.

O custo inicial da protease utilizada foi de US\$27,00/kg e da celulase US\$ 2,25/kg, obtidos por meio da IMCOPA e de Furlan (2012). O preço do etanol foi US\$ 0,69/L obtido no site do Centro de 


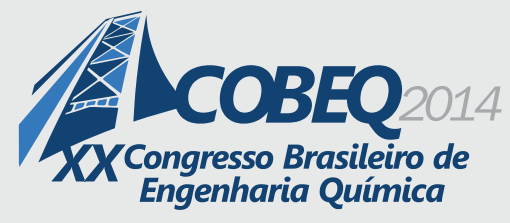

19 a 22 de outubro de 2014
Florianópolis/SC

estudos avançados em Economia aplicada - Cepea (http://cepea.esalq.usp.br/etanol/). Proteína hidrolisada de soja para alimentação animal foi encontrada com preços entre US\$2400 a 2800/ton de um fornecedor.

\section{RESULTADOS E DISCUSSÃO}

Após a primeira simulação do processo, mantendo-se a proporção do volume de água e o tempo de hidrólise da celulose utilizado por Rojas (2012), o processo ficou economicamente inviável, mesmo utilizando valores bem altos para os produtos e diminuindo o valor de insumos.

Posteriormente, a umidade nos reatores foi diminuída. Testes feitos pela IMCOPA (MIRANDA, 2012) mostraram que é possível se realizar a hidrólise enzimática do farelo de soja com $60 \%$ de umidade. Esse valor foi tomado como base e a umidade nos reatores de hidrólise das proteínas, reator de pré-tratamento e hidrólise da celulose foram diminuídas de 90, 80 e 90\%, respectivamente, para aproximadamente $60 \%$ em todos. O tempo de hidrólise foi diminuído para 48 h (DIAS, 2011). Uma vez redefinido o processo, foram estudadas algumas variações nos preços das enzimas e nos valores dos produtos. A Tabela 2 apresenta os valores utilizados para as enzimas e produtos, assim como o valor presente líquido (VPL) e a taxa interna de retorno (TIR) após impostos (34\%), utilizando-se como taxa mínima de atratividade $7 \%$.

Tabela 2 - Resultado das simulações para diferentes valores de enzimas e produtos

\begin{tabular}{|c|c|c|c|c|c|c|}
\hline & \multicolumn{2}{|c|}{ Custo (US\$/kg) } & \multicolumn{2}{c|}{ Preço de venda } & \multicolumn{2}{c|}{ Resultados } \\
\hline & $\begin{array}{c}\text { Novo-Pro } \\
\text { D }\end{array}$ & Acellerase & $\begin{array}{c}\text { Oligopeptídeos } \\
(\text { US\$/kg) }\end{array}$ & $\begin{array}{c}\text { Etanol } \\
(\text { US\$/L) }\end{array}$ & $\begin{array}{c}\text { VPL } \\
\left(10^{6} \text { US\$) }\right.\end{array}$ & TIR (\%) \\
\hline Caso 1 & 27,00 & 2,25 & 2,80 & 0,69 & $-89,326$ & - \\
\hline Caso 2 & 27,00 & 1,13 & 2,80 & 0,69 & $-72,606$ & - \\
\hline Caso 3 & 13,50 & 1,13 & 2,80 & 0,69 & $-66,174$ & - \\
\hline Caso 4 & 13,50 & 1,13 & 6,00 & 0,69 & 8,955 & 7,89 \\
\hline Caso 5 & 13,50 & 1,13 & 6,00 & 0,90 & 12,145 & 8,20 \\
\hline
\end{tabular}

Apesar do custo da enzima Novo-Pro D ser 12 vezes maior do que da Acellerase, a quantidade utilizada é 31 vezes menor. Assim, o custo da Acellerase gera um impacto maior no processo, sendo que para o Caso 1, esta representa $71 \%$ do custo de todos os insumos, enquanto que a Novo-Pro D, $27 \%$ e outros insumos (como $\mathrm{NaOH}, \mathrm{H}_{2} \mathrm{SO}_{4}$, água, etc) totalizam aproximadamente $2 \%$.

Como pode ser observado, com os valores inicias para o custo das enzimas e preço de venda dos produtos, o processo ainda é inviável economicamente. Apenas quando se diminui o preço das enzimas pela metade e utiliza-se pouco mais do que o dobro do preço de venda dos oligopeptídeos em relação aos iniciais é que se passa a ter um processo viável economicamente.

Entre os produtos, o que mais gera renda são os oligopeptídeos, devido a seu maior valor e também à maior quantidade produzida: aproximadamente 3 mil toneladas de oligopeptídeos por ano e 1,9 mil toneladas de álcool por ano. Essa baixa quantidade de etanol se deve à perda de celulose ao longo do processo (aproximadamente 25\%) e à conversão a glicose de apenas $55 \%$ da quantidade que 
chega no reator de hidrólise celulolítica. A quantidade de oligopetídeos obtidos também poderia ser maior, já que apenas $56,9 \%$ do total de proteínas são recuperadas.

A Figura 3 apresenta a variação da TIR para diferentes valores do preço de venda dos oligopeptídeos, fixando-se os outros valores iguais ao do Caso 5.

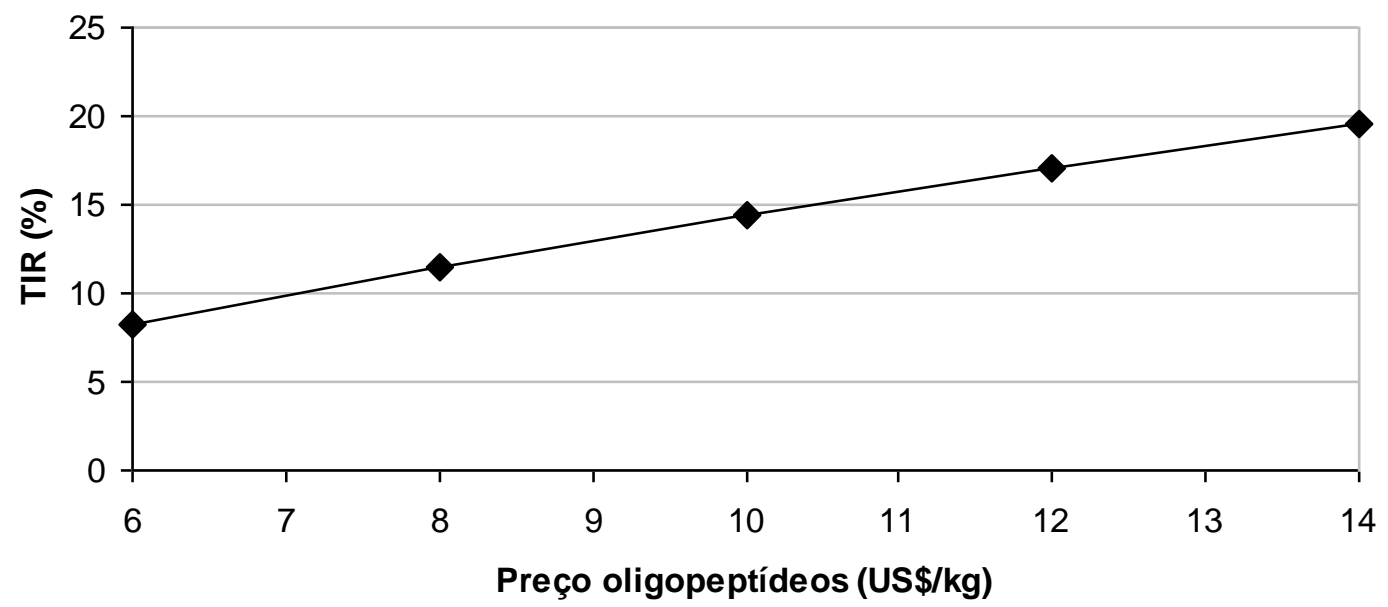

Figura 3 - Variação da TIR com o preço de venda de oligopeptídeos. Os demais insumos e produtos têm custos e preço de venda idênticos aos do Caso 5 da Tabela 2.

De acordo com Apostolakou et al. (2009), processos com TIR menores que 10\% são de alto risco e entre 10 e $15 \%$ de médio risco. Assim, considerar valores de oligopetídeos abaixo de aproximadamente US $\$ 7,00 / \mathrm{kg}$ indicam que o investimento não é recomendado, enquanto que acima de pouco mais de US\$10,00/kg seria optar por um empreendimento com maior segurança.

Uma provável opção para melhorar a viabilidade econômica da produção de oligopeptídeos e etanol a partir da casca seria o desenvolvimento de processos que apresentassem maior rendimento dos produtos, já que existem perdas consideráveis no processo utilizado neste trabalho e baixa conversão de celulose em glicose. Os subprodutos gerados também poderiam ser utilizados, como o licor de pentoses e a lignina. O licor de pentoses poderia ser usado, também, para produção de etanol ou de xilitol, entre outros e a lignina poderia ser, por exemplo, queimada em uma caldeira para gerar vapor e energia para o processo, diminuindo os gastos com estes. Outra opção seria não produzir o etanol, obtendo-se apenas os oligopeptídeos a partir da casca e utilizar o restante do material para produzir vapor e energia para o processo em uma caldeira.

\section{CONCLUSÕES}

A casca da soja é um subproduto do processo de obtenção do óleo e do farelo de soja. Este trabalho teve como objetivo analisar a viabilidade econômica de se utilizar a casca como matériaprima para a produção de oligopeptídeos e etanol em função dos preços dos principais insumos e dos preços de venda dos produtos. 
A partir da simulação do modelo obtido com base em dados da literatura, pôde-se observar que com a capacidade, as operações, os equipamentos e rendimentos utilizados, o processo só começaria a ser viável se as enzimas tivessem seus preços reduzidos pela metade e o preço de venda dos oligopeptídeos fosse pouco mais do que dobrado em relação ao inicial.

\section{AGRADECIMENTOS}

Os autores gostariam de agradecer ao Conselho Nacional de Desenvolvimento Científico e Tecnológico (CNPq), à Coordenação de Aperfeiçoamento de Pessoal de Nível Superior (CAPES) e à IMCOPA - Importação, Exportação e Indústria de Óleos S.A.

\section{REFERÊNCIAS}

APOSTOLAKOU, A. A.; KOOKOS, I. K.; MARAZIOTI, C.; ANGELOPOUlOS, K. C. Techno-economic analysis of a biodiesel production process from vegetable oils. Fuel Proc. Tech., v. 90, p. 1023-1031, 2009.

CEPEA. Indicadores de preço - Etanol. Disponível em http://cepea.esalq.usp.br/etanol/. Acesso em abril de 2014.

CLEMENTE, A. Enzymatic proteins hydrolysates in human nutrition. Trends in Food Sci. \& Tech., v. 11, p. 254-262, 2000.

DIAS, M. O. S. Simulação do processo de produção de etanol a partir do açúcar e do bagaço, visando a integração do processo e a maximização da produção de energia e excedentes do bagaço. 2008. Dissertação (Mestrado em Engenharia química) - Faculdade de Engenharia química, Universidade Estadual de Campinas, Campinas, 2008.

DIAS, M. O. S. Desenvolvimento e otimização de processos de produção de etanol de primeira e segunda geração e eletricidade a partir da cana-de-açúcar. 2011. Tese (Doutorado em Engenharia química) - Faculdade de Engenharia química, Universidade Estadual de Campinas, Campinas, 2011.

FURLAN, F. F. Desenvolvimento de ambiente integrado para simulação e otimização estática da produção de etanol a partir de bagaço de cana-de-açúcar por rota bioquímica. 2012. Dissertação (Mestrado em Engenharia química) - Faculdade de Engenharia química, Universidade federal de São Carlos, São Carlos, 2012.

IMCOPA. Empresa. Disponível em http://www.imcopa.com.br/empresa. Acesso em abril de 2014.

MIELENZ, J. R.; BARDSLEY, J. S.; WYMAN, C. E. Fermentation of soybean hulls to ethanol while preserving protein value. Biores. Tech., v. 100, p. 3532-3539, 2009.

MIRANDA, L. C. Obtenção e caracterização de hidrolisados enzimáticos de proteínas do farelo de soja. 2012. Dissertação (Mestrado em Engenharia química) - Faculdade de Engenharia química, Universidade Federal de São Carlos, 2012.

ROJAS, M. J. Produção de etanol e hidrolisado protéico da casca da soja. 2012. Dissertação (Mestrado em Engenharia química) - Faculdade de Engenharia química, Universidade 
Federal de São Carlos, São Carlos, 2012.

SCHIRMER-MICHEL, A. C.; FLÔRES, S. H.; HERTZ, P. F.; MATOS, G. S.; AYUB, M. A. Z.. Production of ethanol from soybean hull hydrolysate by osmotolerant Candida guilliermondii NRRL Y-2075. Biores. Tech., v. 99, p. 2898-2904, 2008.

SILVA, B. A. N. A casca da soja e sua utilização na alimentação animal. Rev. Eletr. Nutritime, v. 1, n.1, p. 59-68, 2004. 